\title{
EIXOS MOBILIZADORES EM QUÍMICA: UM BREVE OLHAR QUINZE ANOS DEPOIS
}

\author{
Lilian Lefol Nani Guarieiro ${ }^{\mathrm{a}, \mathrm{b}}$, Pedro Afonso de Paula Pereira ${ }^{\mathrm{b}, \mathrm{c}}$, Paulo Cezar Vieira ${ }^{\mathrm{d}}$, Norberto Peporine Lopes $^{\mathrm{d}}$ e Jailson \\ B. de Andrade ${ }^{\mathrm{a}, \mathrm{b} *}$ \\ aCentro Universitário SENAI CIMATEC, 41650-010 Salvador - BA, Brasil \\ 'Instituto Nacional de Ciência e Tecnologia de Energia e Ambiente, Laboratório de Nanomateriais, Universidade Federal da Bahia, \\ 40170-115 Salvador - BA, Brasil \\ 'Instituto de Química, Universidade Federal da Bahia, 40170-115 Salvador - BA, Brasil

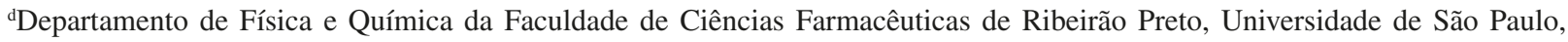 \\ 14040-903 Ribeirão Preto - SP, Brasil.
}

Recebido em 24/09/2018; aceito em 01/10/2018; publicado na web em 04/10/2018

\begin{abstract}
MOBILIZING AXES IN CHEMISTRY: A SHORT LOOK 15 YEARS LATER: In 2002, the Brazilian Chemical Society have promoted several activities aiming to prepare a document to discuss the education in Chemistry in Brazil, the new model of research funding, the area situation and its perspectives. The document drew up diagnoses and brought up proposals that were organized into six mobilizing axes. Among its conclusions it was expected an alignment of scientific and technological research, considering the central role of Chemistry in solving problems and overcoming challenges affecting the education, full citizenship, climate changes, food production and quality, access to and quality of water, energy security, preservation of ecosystems and species, emerging diseases and quality of life. The current moment brings again challenges, imposed by a new technological generation, the transformations of the urban societies and by the commitment with a sustainable development. This article seeks to outline a panorama, using as background the Industry 4.0, the Society 5.0, the Sustainable Development Objectives, the creation of the EMBRAPII, the SENAI Institutes of Innovation and the role of the graduate programs in Chemistry, in order to construct a new agenda under the scope of the SBQ for the next 15 years.
\end{abstract}

Keywords: chemistry in Brazil; mobilizing axes; graduate programs in chemistry; 4.0 industry; sustainable development objectives.

\section{AVISO AOS LEITORES}

Não é pretensão deste texto fazer um exame exaustivo do que ocorreu nestes quinze anos, mas sim fazer algumas reflexões sobre o momento atual com relação aos aspectos relacionados com o EIXO 1 (Eixos Mobilizadores da Química), A Formação do Químico. Serão abordados os avanços resultantes de várias ações desencadeadas pela SBQ e os novos desafios que surgem devido às necessidades da sociedade, do setor industrial e do desenvolvimento sustentável. O objetivo do texto não é estimular outras (os) Colegas a apresentarem as respectivas opiniões sobre os avanços promovidos pela SBQ nos setores químicos acadêmico e empresarial. Alguns trechos de publicações passadas são resgatados, não com o objetivo de repetir o que já foi publicado, mas sim de contextualizar a época em que foram escritos com a situação atual da área de química e do país.

\section{BREVE RETROSPECTIVA}

Em 2002, a Diretoria e o Conselho Consultivo da Sociedade Brasileira de Química, SBQ, decidiram promover uma série de atividades visando à elaboração de um documento denominado "Eixos Mobilizadores da Química" quando foram discutidos o ensino de Graduação e Pós-graduação em Química, o novo modelo de financiamento à pesquisa, a situação da área e as perspectivas, especialmente considerando as eleições para Presidente, Governador, Congresso Nacional e Assembleias Legislativas. ${ }^{1}$

Após uma série de reuniões e discussões, seis eixos foram propostos:

O primeiro eixo mobilizador sugerido, formação de recursos

*e-mail: jailsondeandrade@gmail.com humanos qualificados, foi resultado de uma série de análises comparativas que evidenciaram que para o país dar um salto também em inovação era necessário um investimento significativo na formação de recursos humanos qualificados em profusão e em todos os níveis.

$\mathrm{O}$ segundo eixo mobilizador sugerido foi desconcentração regional e combate à endogenia, resultado da constatação da necessidade de promover a desconcentração regional, sem perda de qualidade, e de combater a endogenia em qualquer das suas expressões - individual, temática ou geracional.

$\mathrm{O}$ terceiro e quarto eixos mobilizadores recomendados foram o estímulo ao empreendedorismo e à interdisciplinaridade e aproximação proativa da academia com a atividade econômica, resultantes de dois desafios de grande relevância naquele momento, que eram estimular o empreendedorismo e promover a "promiscuidade e a poligamia" intelectual, buscando uma aproximação proativa com o setor empresarial.

O quinto eixo mobilizador recomendado foi vinculação orçamentária de recursos para $\mathbf{C \& T}$, que foi o resultado da constatação da necessidade da garantia de recursos financeiros ampliados em volume, continuados, diversificados e regionalmente sustentados.

O sexto eixo mobilizador sugerido foi combate aos gargalos institucionais, pois constatou-se que a estrutura organizacional das instituições de ensino superior apresentava vários gargalos que dificultavam o desenvolvimento da pesquisa, dentre os quais destacavam-se: a estrutura departamental das Instituições de Ensino Superior (IES), que se tornou barreira para a interdisciplinaridade e fonte de duplicação de esforços; o sistema de gestão das IES, desarticulado, lento e dispendioso; a qualificação e gestão de pessoal técnico inadequada para a atividade de pesquisa; serviço de manutenção de equipamentos, inexistente ou deficiente e, finalmente, 
interlocução com o setor industrial deficiente. Além dos gargalos intrainstitucionais apontados, era preciso solucionar problemas relacionados com a importação de equipamentos científicos, e a importação de insumos químicos.

Nas conclusões do documento publicado em Química Nova, há 15 anos $^{1}$ está registrado o seguinte: "Na segunda metade do século $X X$, a pesquisa científica no Brasil deu um salto significativo. Vários fatores contribuíram para isso, merecendo destaque a criação do CNPq e da CAPES na década de 50 e, posteriormente, da FINEP e FAPESP, bem como a institucionalização e avaliação da pós-graduação. Atualmente, a ciência brasileira está diante de uma mudança de paradigma: se na década de 60 bastava ao professor universitário fazer pesquisa, na década de 80 a publicação de papers era condição obrigatória para ser considerado pesquisador. Várias vezes, nas últimas cinco décadas, o desafio (perguntas) apresentado aos professores pesquisadores mudou. Provavelmente, em breve, a "pergunta da vez será": quantos empregos a sua pesquisa gerou? Nesse momento próximo, a sintonia da pesquisa científica e tecnológica com a sociedade será inevitável. No caso específico da área de Química, por ser um ramo da ciência a serviço da humanidade, a sintonia é indissociável. A Sociedade Brasileira de Química, mobilizada e motivada espera, com os Eixos Mobilizadores em Química, contribuir nas mudanças efetivas que potencializem o ensino e a geração, difusão e apropriação do conhecimento."

Dentre os seis eixos identificados, o de maior transversalidade era o da formação de recursos humanos qualificados, pois ele repercute e/ou é afetado pelos demais. Nesse sentido, este foi o eixo mais discutido e "trabalhado", tendo a Diretoria e o Conselho da Sociedade Brasileira de Química (SBQ) decidido aprofundar as discussões sobre a formação de pessoal de alto nível. Após uma sequência de reuniões foi divulgado o documento "A formação do Químico"” que abordava a graduação, pós-graduação, as Diretrizes Curriculares para os Cursos de Química, a situação do setor químico na indústria e destacava os dez mandamentos do Universitário do século XXI, divulgados na Conferência Mundial sobre o Ensino Superior - UNESCO, 1998: (1) Seja flexível, não se especialize demais; (2) Invista na criatividade, não só no conhecimento; (3) Aprenda a lidar com incertezas (o mundo é assim); (4) Prepare-se para estudar durante toda a vida; (5) Tenha habilidades sociais e capacidade de expressão; (6) Saiba trabalhar em grupo, bons empregos exigem isso; (7) Esteja pronto para assumir responsabilidades; (8) Busque ser empreendedor, crie o seu emprego; (9) Entenda as diferenças culturais (o trabalho globalizou); (10) Adquira intimidade com novas tecnologias.

$\mathrm{O}$ documento ${ }^{2}$ finaliza com as seguintes conclusões e desafios: "Nos últimos anos, por força dos processos de avaliação, o ensino superior brasileiro tem mostrado melhora. $O$ número de docentes doutores nas IES tem crescido com rapidez. As condições físicas, os laboratórios, as bibliotecas, as facilidades computacionais em quase todas as instituições estão se transformando para melhor. Porém, conforme já mencionado, no que concerne à formação do Químico, várias questões permanecem inalteradas, comprometendo, definitivamente, a formação do graduado.

Com acertos e erros conceituais e metodológicos amplamente conhecidos e discutidos, os resultados das provas dos estudantes no Exame Nacional de Curso (ENC) ainda não permitem um mapeamento seguro da qualidade curricular e didático-pedagógica dos cursos de Graduação em Química no Brasil. Não se pode, entretanto, deixar de perceber a importância e a gravidade de algumas informações paralelas obtidas através do questionário que os alunos respondem como parte desse Exame. A maioria dos discentes de Química que se submeteu aos ENC de 2000 a 2002 disse que: i) dedicava apenas 5 horas semanais para estudo extra-classe; ii) sabia muito pouco de inglês e de espanhol; iii) lia, em média, um livro por ano e iv) quase não lia jornais. Todavia, $40 \%$ desses discentes disseram que pretendiam trabalhar no ensino; $70 \%$ pretendiam fazer cursos de pós- graduação e mais de $80 \%$ queriam trabalhar na área de Química. Mudanças devem ser introduzidas nos projetos didático-pedagógicos dos cursos para que estes ofereçam uma formação sólida em Química, mas abrangente e generalista o suficiente para que o Químico possa se desenvolver em mais de uma direção. Muitos são os desafios que se nos impõem nessa tarefa de formação do Químico: i) implantar as Diretrizes; ii) melhorar a qualificação para a docência dos professores universitários e do ensino médio; iii) redefinir a formação profissional buscando a formação de um graduado com intimidade com novas tecnologias e com espírito empreendedor; iv) formar pós-graduados com possibilidade de inserção no setor industrial; v) buscar a transformação da indústria química brasileira de indústria de base para indústria de especialidades; vi) buscar a alteração das atribuições profissionais, de modo a eliminar a verticalização de atribuições, e o reconhecimento da pós-graduação como qualificação profissional e vii) responder à questão qual o perfil do profissional de Química que estaremos formando em 5, 10 e 20 anos? Esse é o perfil que a sociedade necessita?"

Em continuidade a essas ações, em 2005, como contribuição à $3^{\mathrm{a}}$ Conferência Nacional de Ciência, Tecnologia e Inovação, a SBQ organizou, em parceria com o Centro de Gestão e Estudos Estratégicos, CGEE, o número especial de Química Nova: Necessidades e Perspectivas da Química no Brasil - O Futuro do Profissional na Pesquisa. ${ }^{3}$

O conteúdo do Volume 28 de Química Nova e da Publicação Parcerias Estratégicas do CGEE foi organizado de modo que os temas abordados incluíssem propostas de políticas e de mecanismos de mobilização visando a sustentação de ações para o futuro imediato da área: ${ }^{4}$ Química no Brasil: Perspectivas e Necessidades Para a Próxima Década: Documento Básico; ${ }^{5}$ seis trabalhos abordaram vários tópicos relacionados à "Formação do químico: desafios e necessidades": - A graduação em Química: um novo químico para uma nova era; ${ }^{6}$ Qual o perfil do profissional de Química que está sendo formado? Esse é o perfil que a sociedade necessita?; ${ }^{7}$ - O estímulo ao empreendedorismo nos cursos de Química: formando químicos empreendedores $;^{8}$ - "Spin-off" acadêmico: criando riquezas a partir de conhecimento e pesquisa; - Informações de patentes: ferramenta indispensável para a pesquisa e o desenvolvimento tecnológico; ${ }^{9}$ - A evasão nos cursos de graduação de Química. Uma experiência de sucesso feita no Instituto de Química da Universidade Federal do Rio de Janeiro para diminuir a evasão. ${ }^{10}$ Cinco trabalhos foram referentes ao tema "Organização da pesquisa e os desafios da interação com áreas do conhecimento": - Contribuição à organização da pesquisa em Química e os desafios da interação com outras áreas do conhecimento - Interfaces e organização da pesquisa no Brasil: da Química à Nanotecnologia; ${ }^{11}$ - Organização da pesquisa no Brasil: lições do passado, propostas para o futuro; ${ }^{12}$ - A questão da inovação em fármacos no Brasil: proposta de criação do Programa Nacional de Fármacos (PRONFAR); ${ }^{13}$ - Interfaces com a indústria. ${ }^{14}$ Três trabalhos abordam a "Política industrial e inovação": Aspectos e fatores da produtividade em pesquisa, desenvolvimento e inovação: ${ }^{15}$ - Inovação e produção em química fina: ${ }^{16}$ - Produção tecnológica e produção no setor químico. ${ }^{17} \mathrm{O}$ tema "A pesquisa a serviço das políticas públicas" é discutido em seis artigos: - Políticas públicas (serviços, inclusão social, saúde pública e metrologia) ${ }^{18}$ O quadrante de Ruetsap e a anti-ciência, tecnologia e inovação; ${ }^{19}$ - Geração do conhecimento através da especificação de produtos químicos $;{ }^{20}$ - A indústria de processamento químico no Brasil: suas motivações para pesquisa e desenvolvimento e suas interfaces com as políticas governamentais; ${ }^{21}$ - Desafios da Química analítica frente às necessidades da indústria farmacêutica; ${ }^{22}$ - A importância do 
observatório de atividades industriais vis-à-vis tendências em ciência, tecnologia e inovação. ${ }^{23}$

Neste Número Especial, dois textos relacionados à formação do Químico, merecem destaque: i) A Graduação em Química: Um Novo Químico para Uma Nova Era; ${ }^{6}$ e ii) Qual é o Perfil do Professional de Química que está sendo formado? Esse é o Perfil de que a Sociedade Necessita? ${ }^{7}$ Os artigos abordaram temas como os fatores que influenciam a qualidade do ensino superior, destacando que, ainda que se pudesse comprovar a ocorrência de uma grande expansão no ensino superior (por exemplo, no período de 1998 a 2001, quando a cada 2,5 dias surgia uma nova IES privada, e, ainda maior no período de outubro de 2001 a julho de 2003, quando a cada 1,2 dia surgia uma nova IES privada) apenas $9 \%$ dos jovens brasileiros entre as idades de 18 a 24 anos estavam matriculados em curso superior nesse período.

Nesse contexto, ainda que fosse incontestável a existência de uma política de expansão do ensino superior no país, não se podia afirmar que havia uma política de ensino superior sustentada na qualidade. Ressalte-se, outrossim, que estava em andamento um forte financiamento direto às IES privadas, via BNDES e crédito educativo, em detrimento do investimento nas IES públicas, que, por muitas razões, inclusive pela concorrência entre os melhores candidatos, sustentam a qualidade do ensino superior nacional. Esses eram alguns dos fatos estruturais dolorosos, mas inolvidáveis - que, envolvendo os alunos e as IES, comprometiam a qualidade do ensino superior praticado no Brasil, com sérios reflexos na área de Química.

Quanto ao perfil do profissional de Química formado, foi destacado que a abrangência do raio de ação da Química e sua interrelação com outras áreas se, por um lado, a fortalecem, por outro resultam em perda de identidade. Nesse sentido o artigo faz uma longa reflexão sobre os setores Acadêmico e Industrial e conclui que: "O perfil do profissional que estamos formando, em linhas gerais, precisa estar sintonizado com as necessidades da sociedade e do setor onde atuará profissionalmente. Nesse sentido, é preciso abordar com urgência: 1. a estratégia de redesenho curricular com foco no APRENDIZADO e não no ENSINO; 2. além da dimensão Técnica, as dimensões Comportamental, Gerencial e Administrativa; 3. a remoção de barreiras burocráticas intra-universidade e profissional; e, 4. como a QUÍMICA se relaciona com outras áreas e o que significa esta relação!

A abordagem destes aspectos traria cunho evolucionário, permitindo ao profissional de Química lidar com os desafios propostos pelo mercado de trabalho. No entanto, para tal, é preciso deflagrar urgentemente nos cursos de Química, Graduação e Pósgraduação, um processo que rompa com o conservadorismo atual e caminhe na direção da formação do profissional que a sociedade necessita. Nada disto terá importância, se não vier alicerçada em uma formação acadêmica e profissional sólida e com alto grau de qualificação."

Já em 2009, como contribuição à $4^{\text {a }}$ Conferência Nacional de Ciência, Tecnologia e Inovação, que ocorreria em 2010, a SBQ organizou outro número especial de Química Nova: Recursos Naturais: Oportunidades na Academia e na Industria. No Editorial é destacado o papel da SBQ na formulação de planos e políticas de desenvolvimento da Química Brasileira em todos os seus aspectos. ${ }^{24}$

Nesse sentido, os artigos publicados abordaram o aproveitamento de recursos naturais, bem como transmitiram e discutiram informações relevantes sob a perspectiva da inovação: - Recursos humanos para novos cenários; ${ }^{25}$ - Aproveitamento sustentável de biomassa e de recursos naturais na inovação química; ${ }^{26}$ - Biomassa e energia; ${ }^{27}$ - Óleos essenciais no Brasil: aspectos gerais, desenvolvimento e perspectivas; ${ }^{28}$ - Database of the Amazon aromatic plants and their essential oils $;{ }^{29}$ - Potencialidades e oportunidades na química da sacarose e outros açúcares; ${ }^{30} ;$ - Gliceroquímica: novos produtos e processos a partir da glicerina de produção de biodiesel $;^{31}$ - Polissacarídeos da biodiversidade brasileira: uma oportunidade de transformar conhecimento em valor econômico; ${ }^{32}$ - Aplicações de fibras lignocelulósicas na química de polímeros e em compósitos; ${ }^{33}$ - Quitosana: biopolímero funcional com potencial industrial biomédico; ${ }^{34}$ - Biodiversidade: fonte potencial para a descoberta de fármacos ${ }^{35}$ Fontes vegetais naturais de antioxidantes $;{ }^{36}$ - Organismos marinhos como fonte de novos fármacos: histórico $\&$ perspectivas ${ }^{37}$ - Fotoprotetores derivados de produtos naturais: perspectivas de mercado e interações entre o setor produtivo e centros de Pesquisa ${ }^{38}$ Feromônios de insetos: tecnologia e desafios para uma agricultura competitiva no Brasil; ${ }^{39}$ - Óleo da castanha de caju: oportunidades e desafios no contexto do desenvolvimento e sustentabilidade industrial; ${ }^{40}$ Transformações biológicas: contribuições e perspectivas $;{ }^{41}$ - Energia, meio ambiente e economia: o Brasil no contexto mundial; ${ }^{42}$ - Biocombustíveis a partir de óleos e gorduras: desafios tecnológicos para viabilizá-los; ${ }^{43}$ - Biodiesel: visão crítica do status atual e perspectivas na academia e na indústria; ${ }^{44}$ Cadeia do biodiesel da bancada à indústria: uma visão geral com prospecção de tarefas e oportunidades para P\&D\&I; ${ }^{45}$ - Modificação química de argilas: desafios científicos e tecnológicos para obtenção de novos produtos com maior valor agregado; ${ }^{46} \mathrm{e}$ - Borracha natural e nanocompósitos com argila. ${ }^{47}$

Neste número especial, a discussão do Eixo 1 a formação do químico avança por meio do artigo Recursos Humanos para Novos Cenários. ${ }^{48}$ No artigo foram abordadas a sustentabilidade e a interdisciplinaridade na formação do Professor de Química e a situação do Setor Industrial Químico, onde destaca-se: “Para enfrentar os desafios dos tempos atuais, em que os mercados de trabalho são cada vez menos previsíveis e se alteram em curto espaço de tempo, é necessário mudar a estrutura dos cursos de graduação e a forma de ensinar. Ciência, técnica e tecnologia correspondem a um trinômio indissociável, e a educação é um processo permanente. Hoje, aprendese ao longo de toda a vida, cujo aumento de expectativa nos últimos 40 anos, ocorreu, graças, em parte, ao avanço da Química. Viver mais e melhor depende, principalmente, do progresso da ciência e do domínio de novas tecnologias. Isto requer mudança de atitudes e da forma de ensinar, e da reorganização dos cursos. Nos cursos de Química, os currículos deverão incluir Programas Temáticos que integrem ciência e educação, e a avalanche de disciplinas teóricas que soterra os estudantes, cujos conteúdos, muitas vezes, se repetem ao longo do curso, ser substituída por um elenco de problemas para os quais os estudantes, individualmente ou em grupo, procurem encontrar soluções. Os estudantes de Química devem aprender desde o início do curso a importância que a propriedade intelectual representa para a riqueza nacional. Invenções, sejam elas incrementais ou radicais, só se transformam em riqueza se forem protegidas por patentes. As Licenciaturas em Química deverão também formar professores para o Ensino Médio que, além do domínio de conteúdos, sejam conscientes da missão de formar cidadãos que reconheçam a importância da ciência para o bem-estar da humanidade".

Também em 2009, a Diretoria e o Conselho decidiram ampliar a linha editorial da SBQ com a criação do portal Química Nova Interativa, QNint, ${ }^{49}$ destinado a reforçar o lema da linha editorial e para servir de instrumento de conexão entre Ciência e Educação. Concebida como "uma flecha que mira o futuro", que pretende ser "uma metamorfose ambulante"! QNInt é o Portal do Conhecimento da SBQ, cujo objetivo é prover instrumentação confiável para a formação em Química, a ser utilizada por estudantes e professores em todos os níveis de formação, primando pela interatividade e pela atualização das informações. É a conexão entre Ciência e Educação em Química acessivelmente disponibilizada! 
Em 2012, a Diretoria e o Conselho Consultivo da SBQ criaram uma comissão integrada pelos ex-Presidentes: Angelo C. Pinto, César Zucco, Fernando Galembeck, Paulo C. Vieira e Jailson B. de Andrade, para a realização do "Censo da Química no País". A primeira ação desenvolvida foi deflagrar, ainda em 2012, a discussão, através do artigo Química sem Fronteiras,$^{50}$ convidando a comunidade de Química a debater a questão e a contribuir com position papers temáticos e em áreas estratégicas, que foram consolidados em outubro de 2013 e fazem parte da contribuição da SBQ ao Fórum Mundial de Ciências, que ocorreu no Rio de Janeiro em novembro de 2013.

Nesse $\operatorname{artigo~}^{50}$ foi destacado que "Os grandes desafios atuais e futuros do planeta e da humanidade são: educação; cidadania plena; mudança climática; produção e qualidade dos alimentos; acesso e qualidade da água; segurança energética; preservação de ecossistemas e das espécies; doenças emergentes e qualidade de vida". Como ponto de partida eram considerados, dentre outros, os seguintes temas centrais e transversais: i) Temas centrais: educação (todos os níveis); vida (incluindo fármacos e medicamentos); matérias-primas e materiais, "novos e velhos" (incluindo nanociência e nanomateriais); biodiversidade, (incluindo recursos naturais não minerais); energia, água, alimentos e ambiente, inovação e a indústria química; ii) Temas transversais: ética e integridade científica; avaliação; inovação; agregação de valor; marcos legais e emergências.

O panorama da Química retratava, que, em 2012, A indústria química brasileira era a $7^{a}$ do mundo, contribuindo para que o PIB brasileiro ocupe a $6^{a}$ posição, revelando um grave descompasso entre a importância dada à educação em Química - em especial nos cursos de graduação e licenciatura - e a importância da Química nos demais setores da vida nacional. "Aproximar a produção química (que sustenta a indústria em geral, pela sua contribuição em energia e materiais) da educação química (que forma os profissionais da área) parece ser um desafio crucial deste momento histórico: garantir o desenvolvimento economicamente viável, com métodos e tecnologias inovativas e ambientalmente sustentáveis. ${ }^{51}$

Quando em 2013 o número especial (NE) de Química Nova, Química Sem Fronteiras foi publicado o editorial ${ }^{52}$ que fez a sua apresentação destacava que: Como parte das atividades do Fórum Mundial de Ciência que ocorreu no Rio de Janeiro, nos dias 25 e 26 de novembro de 2013, cujo tema foi Ciência para o Desenvolvimento Global, a SBQ publicou este número especial de Química Nova, em que especialistas apresentaram o Estado da arte de assuntos de grande importância para o desenvolvimento brasileiro e para a ciência mundial. Estes assuntos vão desde a "Imagem pública e divulgação da química: desafios e oportunidades" a "A química na agricultura: perspectivas para o desenvolvimento de tecnologias sustentáveis". Os artigos publicados abordaram os seguintes temas: - Química e sustentabilidade: novas fronteiras em biocombustíveis: ${ }^{53}$ - Inovação \& propriedade industrial \& indústria química $;{ }^{54}$ - Oceanografia e Química: unindo conhecimentos em prol dos oceanos e da sociedade:55 - A química na agricultura: perspectivas para o desenvolvimento de tecnologias ${ }^{56}$ - Carboidratos como fonte de compostos para a indústria de química fina; ${ }^{57}$ - Impactos da nanotecnologia na saúde: produção de medicamentos; ${ }^{58}$ - Panorama de propriedade intelectual, transferência de tecnologia e inovação da química brasileira e a comparação com os países do BRIC; $;^{59}$ - Nanoestruturas de carbono (nanotubos, grafeno): quo vadis?; ${ }^{60}$ - Química sem fronteiras: o desafio da energia ${ }^{61}$; - Doenças tropicais negligenciadas: uma nova era de desafios e oportunidades; ${ }^{62}$ - Desafios da indústria farmacêutica brasileira; ${ }^{63}$ - Imagem pública e divulgação da química: desafios e oportunidades $;{ }^{64}$ - A pesquisa em ensino de química como área estratégica para o desenvolvimento da química; ${ }^{65}$ Explorando produtos naturais microbianos nas fronteiras da química e da biologia; ${ }^{66}$; Fatos e tendências da biocatálise ${ }^{67}$ - Catálise assimétrica no Brasil: desenvolvimento e potencialidades para o avanço da indústria química brasileira; ${ }^{68}$ - Inovação para a sustentabilidade $;{ }^{69}$ e - Metabolômica, uma abordagem otimizada para exploração da biodiversidade brasileira: estado da arte, perspectivas e desafios. ${ }^{70}$

Ainda em 2013, um grupo de trabalho formado pelo Presidente da SBQ, Vitor Ferreira e pelos ex-presidentes Ângelo da Cunha Pinto, César Zucco e Jailson B. de Andrade, foi encarregado de elaborar as bases para o projeto de Mestrado Profissional em Química, $\mathrm{PROFQUIM}^{71}$ que atendesse às eventuais necessidades do país nesse campo de formação superior. O projeto contou com a colaboração de professores e de instituições de ensino, convidados a participar de sua elaboração, de forma a ganhar amplitude e representatividade. A proposta para o curso era de que fosse oferecido na modalidade presencial utilizando também ferramentas de ensino a distância. Nessa concepção, foi previsto que os conteúdos do portal QNInt - Química Nova Interativa, e das revistas Química Nova, Química Nova na Escola e Revista Virtual de Química deveriam ser adequados à grade curricular do curso para acesso eletrônico. Supunha-se também a definição de uma instituição de ensino como sede básica do curso, atuando em rede com outras instituições.

Ao ser criado, o Mestrado Profissional em Química em Rede Nacional - PROFQUIM ${ }^{72}$ fez a sua primeira seleção de estudantes em 2017, um programa de pós-graduação semipresencial, stricto sensu, na modalidade mestrado profissional na área de Química com oferta nacional. Ele é formado por uma rede de Instituições de Ensino Superior, no contexto da Universidade Aberta do Brasil/Coordenação de Aperfeiçoamento de Pessoal de Nível Superior (CAPES), e coordenado pelo Instituto de Química da Universidade Federal do Rio de Janeiro, tendo a cogestão da SBQ e o apoio das Instituições Associadas. Sem dúvida, o PROFQUIM foi uma das boas inciativas lideradas pela SBQ visando a melhoria da qualificação profissional do Professor de Química, em consonância assim com a permanente atenção aos eixos propostos no documento seminal de 2003 (EMeQ).

Esse texto descreve até aqui, de forma sucinta, como a SBQ e, em especial, os "Eixos Mobilizadores em Química" influenciaram o desenvolvimento da Química no Pais. Todo o esforço culminou com a realização de um sonho coletivo em 2017: pela primeira vez um Congresso Mundial de Química, organizado pela IUPAC, ocorreu no circuito América do Sul-África: a 40ª Reunião Anual da Sociedade Brasileira de Química, o 46 ${ }^{\text {th }}$ World Chemistry Congress e a $49^{\text {th }}$ General Assembly, da IUPAC, foram realizados conjuntamente no período de 7 a 13 de julho de 2017 em São Paulo, Brasil. Este evento simbolizou o compromisso de todas as Diretorias, Conselhos Consultivos, Secretarias Regionais e Divisões da SBQ, num trabalho concertado por quatro décadas mirando o futuro. Neste contexto, os "Eixos Mobilizadores em Química" representaram a "estratégia dos últimos quinze anos". E agora? Qual o novo desafio?

\section{A ATUALIDADE}

Neste século, o grande consumo de matérias-primas deve ser substituído, em vários setores, pelo reuso e reciclagem. Pelo menos outras duas mudanças significativas são necessárias: a migração do uso intensivo de combustíveis fósseis para o uso de energia renovável; e a transição do controle de efluentes para a economia de átomos. Essas mudanças representarão importante passo para a economia de recursos naturais e de recursos financeiros e para proteção ao ambiente e à vida, requerendo forte interação com instituições acadêmicas e tecnológicas.

Mimetizando "o olhar de Janus"73 tentaremos abordar, brevemente, alguns desafios atuais e urgentes às necessidades da sociedade, do setor industrial e do desenvolvimento sustentável, utilizando, como pano de fundo: 1. os Objetivos do Desenvolvimento 
Sustentável (ODS); 2. a Industria 4.0 e a Industria Química; 3. a Sociedade 5.0; 4. a criação da EMBRAPII, dos Institutos SENAI de Inovação Tecnológica e a Formação e Modelos de Negócio de Base Tecnológica; e 5. o papel da Pós-graduação em Química neste cenário, considerando também a criação recente dos Mestrados Profissionais e a perspectiva de criação de Doutorados Profissionais, no momento em que este artigo é escrito. Estes exemplos têm por objetivo destacar alguns temas recentes, que tiveram especial destaque após a agenda proposta nos "Eixos Mobilizadores em Química" e assim estimular a construção de uma nova agenda, no âmbito da SBQ, que sinalize para os próximos 15 anos.

\section{Objetivos para um Desenvolvimento Sustentável (ODS)}

Os ODS representam uma agenda para o Planeta e para a Humanidade. Os 17 ODS e suas 169 metas têm como foco o Planeta - Proteger os recursos naturais e o clima do nosso planeta para as gerações futuras; Pessoas - Erradicar a pobreza e a fome de todas as maneiras e garantir a dignidade e a igualdade; Prosperidade Garantir vidas prósperas e plenas, em harmonia com a natureza; Paz - promover sociedades pacificas, justas e inclusivas; e Parcerias Implementar a agenda por meio de parceria global sólida, estimulando as parcerias nos países e entre as nações. ${ }^{74}$

Os ODS deverão orientar as políticas nacionais e as atividades de cooperação internacional até 2030, sucedendo e atualizando os Objetivos de Desenvolvimento do Milênio (ODM). O Brasil participou de todas as sessões da negociação intergovernamental que levaram à assinatura do acordo. Brevemente, os 17 ODS são (Figura 1): Objetivo 1. Acabar com a pobreza em todas as suas formas, em todos os lugares; Objetivo 2. Acabar com a fome, alcançar a segurança alimentar e melhoria da nutrição e promover a agricultura sustentável; Objetivo 3. Assegurar uma vida saudável e promover o bem-estar para todos, em todas as idades; Objetivo 4. Assegurar a educação inclusiva e equitativa e de qualidade, e promover oportunidades de aprendizagem ao longo da vida para todos; Objetivo 5. Alcançar a igualdade de gênero e empoderar todas as mulheres e meninas; Objetivo 6. Assegurar a disponibilidade e gestão sustentável da água e saneamento para todos; Objetivo 7. Assegurar o acesso confiável, sustentável, moderno e a preço acessível à energia para todos; Objetivo 8. Promover o crescimento econômico sustentado, inclusivo e sustentável, emprego pleno e produtivo e trabalho decente para todos; Objetivo 9. Construir infraestruturas resilientes, promover a industrialização inclusiva e sustentável e fomentar a inovação; Objetivo 10. Reduzir a desigualdade dentro dos países e entre eles; Objetivo 11. Tornar as cidades e os assentamentos humanos inclusivos, seguros, resilientes e sustentáveis; Objetivo 12. Assegurar padrões de produção e de consumo sustentáveis; Objetivo 13. Tomar medidas urgentes para combater a mudança do clima e seus impactos; Objetivo 14. Conservação e uso sustentável dos oceanos, dos mares e dos recursos marinhos para o desenvolvimento sustentável; Objetivo
15. Proteger, recuperar e promover o uso sustentável dos ecossistemas terrestres, gerir de forma sustentável as florestas, combater a desertificação, deter e reverter a degradação da Terra e deter a perda de biodiversidade; Objetivo 16. Promover sociedades pacíficas; e Objetivo 17. Fortalecer os meios de implementação e revitalizar a parceria global para o desenvolvimento sustentável.

Uma vez mais, fica clara a percepção de que a educação (em todos os níveis) configura-se num instrumento fundamental para atingir os ODS e implementar a agenda $2030 .{ }^{75}$ Nesse sentido, merecem atenção especial o ODS 4 - Assegurar a educação inclusiva e equitativa e de qualidade, e promover oportunidades de aprendizagem ao longo da vida para todos e o ODS 10 - Redução das desigualdades, os quais impactam e são impactados pelos demais ODS.

\section{Industria 4.0}

No setor empresarial, a inovação está também relacionada à manufatura avançada, igualmente nominada Indústria Inteligente ou Indústria 4.0, terminologia adotada pelos alemães, a qual refere-se à $4^{\mathrm{a}}$ revolução industrial. Caracterizada pela integração e o controle remoto da produção, a partir de sensores e equipamentos conectados em rede, associados a sistemas ciberfísicos, é entendida como o futuro da produção, dentro de um esforço para revitalização das empresas e pela busca de liderança tecnológica e, consequentemente, de mercados globais, cada vez mais competitivos.

Em documento recente, a Confederação Nacional da Indústria ${ }^{76}$ destaca que a ampliação da capacidade de inovação é fundamental para a melhoria da competitividade empresarial. O Mapa Estratégico elaborado pela CNI propõe como meta elevar a taxa de inovação nas empresas brasileiras, de $36,4 \%$ para $45 \%$. Porém, a capacidade de inovação das empresas brasileiras é pouco desenvolvida e segundo uma pesquisa do Fórum Econômico Mundial de 2017, de um conjunto de 137 países, o Brasil está na $85^{\text {a }}$ posição.

De acordo com a ABIQUIM, o setor industrial químico do Brasil ocupa a oitava posição mundial, tendo apresentado um faturamento líquido em 2016 da ordem de US\$ 113,5 bilhões e déficit de US\$ 22,1 bilhões, representando atualmente $2,5 \%$ do PIB brasileiro, enquanto que em 2004 representava um porcentual maior $(3,6 \%)$. Vale ressaltar que mais da metade do faturamento deste setor $(54,9 \%)$ é com produtos químicos de uso industrial, ou seja, produtos com baixo valor agregado. ${ }^{77}$

Ampliar a taxa de inovação das empresas e o faturamento do setor químico com produtos de maior conteúdo tecnológico é um desafio permanente. O setor químico industrial, em escala global e no Brasil, é um dos maiores investidores em pesquisa e desenvolvimento, com índices crescentes de inovação. Todavia, o seu maior desafio atual se refere à sustentabilidade, que consiste em desenvolver produtos e processos com menor demanda por energia, agregando maior competitividade econômica e, especialmente, não agredindo o ambiente e a vida. Isto inclui o estabelecimento e/ou a potencialização
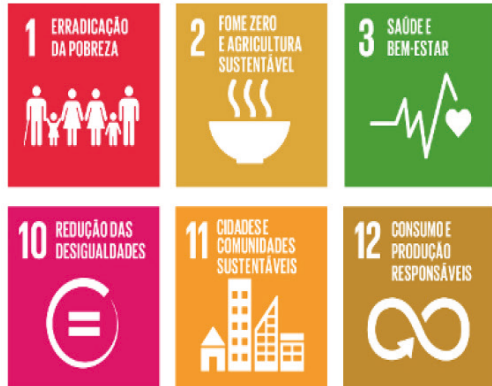
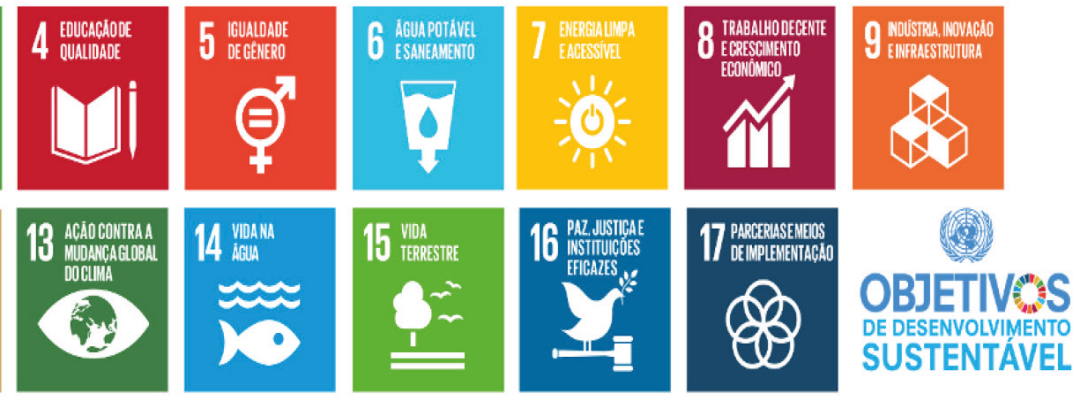

Figura 1. Objetivos para um Desenvolvimento Sustentável (ODS). Fonte https://nacoesunidas.org/pos2015/agenda2030/ acessado em 20/04/2018.75 
de conexões estratégicas entre pesquisa básica, desenvolvimento tecnológico, inovação e articulação social.

Vale destacar que a origem do conceito de Indústria 4.0 está no documento Estratégia de Alta Tecnologia do Governo Alemão ${ }^{78}$ que define seis campos de prioridade: i) A economia digital e a sociedade; ii) A economia sustentável e energia; iii) O local de trabalho inovador; iv) Vida saudável; v) Mobilidade Inteligente; e vi) Segurança civil. Esses campos relacionam diretamente a indústria 4.0 com a Sociedade 5.0.

\section{Sociedade 5.0}

A Concepção de Sociedade 5.0 surge no Japão, no âmbito do "5 Plano Básico de Ciência e Tecnologia", como uma sociedade futura na qual o Japão deveria se inspirar. Esta nova sociedade dá sequência à sociedade de caçadores coletores (Sociedade 1.0), à sociedade agrícola (Sociedade 2.0), à sociedade industrial (Sociedade 3.0) e à sociedade da informação (Sociedade 4.0). Em resumo, "Uma sociedade centrada nas pessoas que equilibra o avanço econômico com a resolução de problemas sociais por um sistema que integra altamente o ciberespaço e o espaço físico." 79

A sociedade 5.0 pode ser considerada como superinteligente, superconectada, altamente cooperativa e também mais velha. No Japão, por exemplo, cerca de $26 \%$ da população atual têm mais de 65 anos. Em escala global, a população de "jovens" com mais de 80 anos, dobra a cada 25 anos desde $1950 .{ }^{80}$

A previsão é que em 2050 a população mundial com mais de 80 anos será cerca de 379 milhões de pessoas e que seis países terão mais de 10 milhões de habitantes com mais de 80 anos. Entre estes países estará o Brasil (Figura 2). Nesse novo cenário, a concepção de qualidade de vida passa a ter novo significado, tornando necessária a construção de uma agenda sustentável para a Humanidade e para o Planeta.

Nos últimos quinze anos, os meios disponíveis para atingir os ODS e dar suporte para a implementação da Industria 4.0 e a Sociedade 5.0 se ampliaram consideravelmente, com a expansão do número de Universidades Públicas e de Institutos Federais de Ensino Tecnológico, com a criação da EMBRAPII e dos Institutos SENAI de Tecnologia e de Inovação, bem como com a aprovação do Marco Legal da Ciência Tecnologia e Inovação que, em conjunto, ampliaram as possibilidades de cooperação cientifica e tecnológica entre os setores acadêmico e empresarial; destaque-se também a criação de novos empreendimentos, como por exemplo, as Startup e/ou as Spin-off, temas abordados a seguir nesse texto.

\section{EMBRAPII}

A EMBRAPII (Associação Brasileira de Pesquisa e Inovação Industrial $)^{81}$ é qualificada como uma Organização Social pelo Poder Público Federal desde setembro de 2013 e tem como finalidade fomentar projetos de cooperação envolvendo empresas nacionais, instituições tecnológicas ou instituições de direito privado sem fins lucrativos, voltadas para atividades de pesquisa e desenvolvimento, que objetivem a geração de produtos e processos inovadores. Inicialmente, a concepção da EMBRAPII foi experimentada como programa piloto em três grandes centros de Pesquisa Brasileiros (INT - Instituto Nacional de Tecnologia no Rio de Janeiro, IPT Instituto de Pesquisas Tecnológicas do Estado de São Paulo e SENAI CIMATEC - Centro de Tecnologia de Salvador). O modelo aprovado e comprovado através do Piloto executado, viabiliza o desenvolvimento de pesquisas de inovação, onde a EMBRAPII entra com um terço dos recursos do projeto, que não é reembolsável, o Instituto credenciado também entra com um terço (na forma de mão de obra e instalações) e o restante é aplicado pela empresa. ${ }^{82}$

Atualmente, a EMBRAPII possui 28 Instituições credenciadas que atuam em 31 diferentes tipos de competências e mais de 100 diferentes linhas de pesquisa, distribuídas em todo Brasil. O modelo EMBRAPII traz uma nova proposta de investimento e flexibilização na aprovação de pesquisas e de inovação, que muito contribui para o avanço das empresas que necessitam inovar num curto espaço de tempo. Além disso, aproxima de forma mais efetiva as indústrias das instituições de pesquisa, induzindo e fomentando a interação entre as empresas, universidades e centros de pesquisa, de forma a diminuir o gargalo de integração existente. Deve-se ressaltar que a EMBRAPII vem fazendo um importante papel na aproximação e no fomento de atividades que envolvem a participação industrial e acadêmica / tecnológica.

\section{Institutos SENAI de Tecnologia e Inovação}

Adicionalmente à EMBRAPII, outra iniciativa recente do setor industrial e que poderá ter papel altamente relevante na conexão com Universidades e Centros de Pesquisa são os Institutos SENAI de Tecnologia e os Institutos SENAI de Inovação. Tais Institutos fazem parte das unidades do SENAI, possuindo infraestrutura física moderna, bem equipada e pessoal treinado e qualificado para a prestação de uma ampla gama de serviços técnicos especializados, com o objetivo de aumentar a competitividade de indústrias de todos os portes. Os Institutos desenvolvem soluções com base nas tecnologias existentes para criar novos processos e novos produtos. Atualmente,

\section{9}

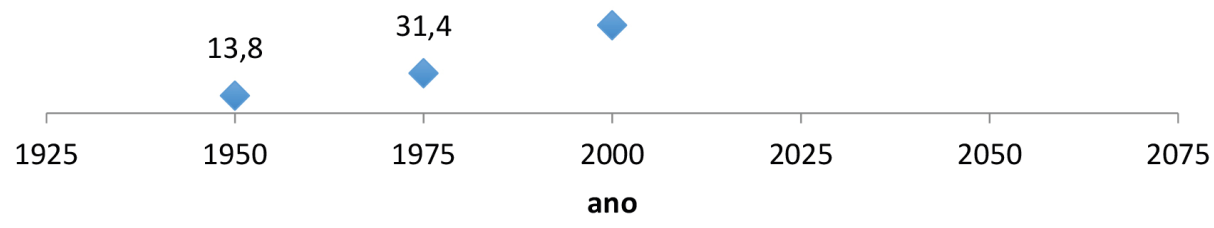

Figura 2. Evolução da população com mais de 80 anos. 
o SENAI possui uma rede com 39 Institutos de Tecnologia em operação e até o final de 2018, pretende inaugurar 25 Institutos SENAI de Inovação. ${ }^{83,84}$ Vale ressaltar que o SENAI inaugurado em 2002, selecionado como unidade piloto da EMBRAPII, além de possuir institutos SENAI de inovação e tecnologia, também possui atualmente o Centro Universitário SENAI CIMATEC, oferecendo ensino superior com nove opções na área de Engenharia, diversos cursos de pós-graduação lato sensu (especializações, MBAs e MBI) e dois programas de pós-graduação stricto sensu (com cursos de mestrado e doutorado) ${ }^{85}$

\section{Formação e Modelos de Negócio de Base Tecnológica: Startups e Spin-off}

Em matéria publicada no jornal britânico The Daily Telegraph, Monday 19 March 2018 page 4 Special, Technology Intelligence, From Roundabout to Revolution, ${ }^{86}$ é destacado o sucesso do "Vale do Silício de Londres" criado há dez anos: ... "London's "Silicon Valley' is no longer something to joke about - but a multi billion pound industry. ...Indeed, by some measures, such as starts-up per capta, Britain now beats the United States. Last year, London raised more than twice the amount of money to fund digital companies than any other city in Europe." Após apresentar o investimento realizado no período 2012-2016, a matéria destaca: "One reason is obvious. Britain is home to eight of Europe's top 20 universities. The "golden triangle" of Oxbridge and London alone offers six within a 60-mile radius." O que comprova, mais uma vez, a importância das Research Universities na geração de conhecimento e riqueza e, especialmente, na criação de Startups e Spin-off.

Na presente discussão é importante entendermos também as estratégias dentro do modelo de negócio da empresa, pois diferentes tecnologias podem ser geridas em modelos de Startup ou Spin-off. Conceitualmente, uma Startup é uma empresa emergente, que acabou de ser criada, a partir de um modelo de negócio com grande potencial, mas cercado de extrema incerteza. Ou seja, o risco no desenvolvimento do novo processo (ou produto, ou serviço, ou plataforma) é grande. Por outro lado, normalmente o retorno, no caso de sucesso, é alto o que chama a atenção de investidores de risco como Capitais de Risco ou Anjos. Cabe destacar que as empresas do tipo Startup podem ou não serem geridas em outros ambientes de pesquisa. Às vezes um pesquisador bem formado pode ter uma nova ideia e esta ser totalmente gerida dentro da empresa emergente sem nenhuma relação prévia com centros de pesquisas das universidades ou de outras empresas. Apesar de parecer fora do contexto colaborativo entre Universidades e Empresas essa colocação nos remete à preocupação de formarmos empreendedores com alta capacidade criativa, além de um sólido conhecimento em Química. Portanto, totalmente dentro da preocupação do primeiro, do terceiro e do quarto eixos mobilizadores do documento anterior.

Por outro lado, as empresas do tipo Spin-off são conceitualmente empresas que derivam de algum núcleo de pesquisa (público ou privado) e normalmente utilizam modelos de incubadores de empresas para seu nascimento. Aqui cabe a observação que quando nascente de uma Universidade essas empresas recebem a denominação de Spin-off Acadêmico. Uma Spin-off pode ser também uma empresa Startup, pois existe a possiblidade de sobreposição dependendo de seu modelo de negócio. Uma rápida busca nos modelos de negócios, em gestação no país, revela que existem nos centros de incubação diversos modelos de Spin-off que alcançam produtos ou serviços com menor taxa de risco e chegam a um mercado carente, como o Brasileiro, em menor tempo. Ainda dentro desse modelo devemos destacar as empresas Spin-off que trabalham no modelo Kibs (KnowledgeIntensive Business Services) que atuam com pesquisa avançada e de alto valor agregado na resolução de problemas para empresas maiores. Esse modelo ainda é pouco explorado no Brasil e existe uma carência do mercado nacional que busca esses serviços no exterior. Nesse contexto, a formação de mão de obra qualificada em nível de pós-graduação na área de química, mas com conhecimento nas diferentes vertentes de gestão e empreendedorismo e com treinamento apropriado, continua sendo um grande desafio e seguramente irá nos levar a um maior desenvolvimento econômico. ${ }^{87}$

Para ilustrar, basta analisarmos que nas últimas décadas a criação de Startups e ou Spin-off vem se configurando em um dos caminhos mais promissores para a inovação com sucesso e retorno a curto prazo. Registros descrevem que, na década de 90, houve uma grande explosão de empresas Startups de tecnologia, o que mostra o grande interesse por este caminho de inovação. ${ }^{88}$ Segundo a Associação Latino-Americana de Fundos de Capital de Risco (LAVCA), o valor investido em Startups brasileiras por fundos de venture capital cresceu $207 \%$ em 2017 e atingiu o patamar recorde de US\$ 860 milhões (cerca de R $\$ 2,86$ bilhões). ${ }^{89}$ Isto demonstra o interesse crescente de investimentos nesse setor e traz incentivos para que instituições e empreendedores se debrucem sobre as suas ideias inovadoras para que estas possam ir para o mercado.

Infelizmente, a criação de programas de Startups e de Spin-off ainda não é realidade para muitas universidades que atualmente possuem como motivação somente a pesquisa e as publicações em periódicos. Todavia, por um outro lado, a indústria valoriza a relação custo-benefício e tem urgência para levar ao mercado a ideia inovadora desenvolvida. Desse modo, a sinergia Academia/Indústria pode ser intensificada através deste viés, sendo um dos grandes desafios a serem superados a mudança de atitudes em prol de um objetivo final unidirecional. Deve-se destacar ainda que a criação de Spin-off acadêmicos seguramente ajuda a que as pesquisas em universidades sejam "traduzidas" para o setor produtivo, uma vez que toda a etapa de prova de conceito da tecnologia é realizada dentro do ambiente de incubadoras, o que garante uma maior chance de sucesso.

Muitos incentivos vêm sendo concedidos, até pelo próprio governo federal, para que o ecossistema de empreendedorismo, inovação e Startups e Spin-off esteja cada vez mais ativo dentro das Universidades e Instituições de pesquisa, intensificando assim a relação das industrias com o meio acadêmico. Nesse aspecto cabe destacar o Decreto $N^{\circ}$ 9.283, o qual alterou várias leis que compõem o Marco Legal da Ciência e Tecnologia. O documento traz uma série de novidades com impactos relevantes para o setor, onde pode-se destacar: i) a autorização para universidades e centros de pesquisa públicos, agências de fomento, empresas públicas e sociedades de economia mista participarem como sócias minoritárias do capital social de empresas inovadoras, seja diretamente ou através de fundos de investimentos; ii) atualização e ampliação dos diferentes mecanismos de fomento à inovação, como o bônus tecnológico que permite que universidades compartilhem sua infra-estrutura de pesquisa com empresas, ou a encomenda tecnológica, que permite que o governo faça encomendas a universidades, inclusive em consórcio com empresas, de soluções tecnológicas para necessidades da administração pública; iii) simplificação de processos de compra de insumos destinados a atividades de pesquisa e desenvolvimento, especialmente nos casos de insumos internacionais (um problema muito conhecido de pesquisadores do país). As importações para esse fim ficarão dispensadas de controles prévios ao despacho aduaneiro e terão a documentação exigida simplificada; $e$ iv) o aumento de carga horária permitida ao pesquisador de instituições públicas para participar de atividades de pesquisa junto ao setor privado. ${ }^{90}$

Neste sentido, o estímulo à criação de programas de Startups e/ ou Spin-off conectados com o meio acadêmico, traz a oportunidade de não só avançarmos para nos tornar um celeiro de ideias novas 
e criativas, mas também de criarmos ambientes propícios para o desenvolvimento das mesmas e seguramente um ambiente profícuo de trabalho para os doutores e mestres formados no país.

\section{UNIVERSIDADES / QUÍMICA /PASSADO E FUTURO}

No início desta década o Congresso dos Estados Unidos da América, preocupado com a situação das Universidades Americanas, deflagrou um processo que resultou na elaboração do documento "Research Universities and the Future of America: Ten Breakthrough Actions Vital to Our Nation's Prosperity and Security." ${ }^{91}$ Merecem atenção especial: i) a motivação do documento; ii) a resposta das Academias de Ciências; iii) o foco das dez sugestões; e iv) as sugestões.

A motivação do documento: Expressing concern that the nation's universities are at risk, the U.S. Congress asked the National Academies to assess the competitive position of America's research universities, both public and private, and to respond to the following question: What are the top 10 actions that Congress, the federal government, state governments, research universities, and others can take to assure the ability of the American research university to maintain the excellence in research and doctoral education needed to help the United States compete, prosper, and achieve national goals for health, energy, the environment, and security in the global community of the 21 st century?

A resposta: In response, the National Research Council convened a committee of individuals who are leaders in academia, industry, government, and national laboratories.

The committee's report, Research Universities and the Future of America, explains its findings and the 10 actions it recommends. This booklet summarizes those findings and recommendations, and highlights several examples of how university research has contributed to discovery and progress.

O primeiro parágrafo: America is driven by innovation advances in ideas, products, and processes that create new industries and jobs, contribute to our nation's health and security, and support a high standard of living. In the past half-century, innovation itself has been increasingly driven by educated people and the knowledge they produce. Our nation's primary source of both new knowledge and graduates with advanced skills continues to be our research universities.

O foco das dez sugestões: Revitalizing the partnership. The first four actions will strengthen the partnership among universities, federal and state governments, philanthropy*, and the business community in order to revitalize university research and speed its translation into innovative products and services; Strengthening institutions. The next three actions will streamline and improve the productivity of research operations within universities; Building talent. The final three actions will ensure that America's pipeline of future talent in science, engineering, and other research areas remains creative and vital, leveraging the abilities of all of its citizens and attracting the best students and scholars from around the world.

As Ações: Research Universities and the Future of America: Ten Breakthrough Actions Vital to Our Nation's Prosperity and Security, NAS: 1. Federal Action; 2. State Action; 3. Strengthening Partnerships with Business; 4.Improving University Productivity; 5. A Strategic Investment Program; 6. Full Federal Funding of Research; 7. Reducing Regulatory Burdens; 8.Reforming Graduate Education; 9 STEM Pathways and Diversity e 10. International Students and Scholars.
Desde o início o documento deixa claro o papel das Research Universities na produção do conhecimento associado à geração de riqueza, melhoria na qualidade de vida e descoberta/formação de "talentos". Em resumo, as Research Universities não representam despesa para o país, mas sim investimento. Como tal, são um patrimônio de alto valor para a nação pois impactam no presente e, especialmente, no futuro! Nesse sentido, em qualquer discussão sobre o futuro da Ciência (que inclui naturalmente o futuro da Química) é fundamental incluir como um tema o papel das universidades brasileiras na formação de recursos humanos altamente qualificados, na geração de riqueza e na redução das desigualdades sociais e regionais do nosso país.

\section{A PÓS-GRADUAÇÃO EM QUÍMICA: UM BREVE OVERVIEW}

Recentemente, em 2017, foi publicado o artigo "A IMPORTÂNCIA DA SOCIEDADE BRASILEIRA DE QUÍMICA NA PÓSGRADUAÇÃO EM QUÍMICA NO BRASIL", ${ }^{92}$ do Presidente da SBQ, Professor Aldo Zarbin, onde é destacado o papel da SBQ no fortalecimento da Pós-graduação em Química "Esse patamar de excelência foi alcançado pela força e comprometimento com que a $S B Q$ atuou (e atua) nos diferentes segmentos em que interfere, como no sistema nacional de Pesquisa e Pós-Graduação, especificamente demonstrado nesse artigo." ... "a grande comunidade da Química brasileira precisa entender definitivamente que não há uma ciência forte sem uma Sociedade Científica forte por detrás. As centenárias Royal Society of Chemistry e American Chemical Society, com seus mais de 150.000 sócios, são exemplos claros da inequívoca correlação entre a qualidade da Química que se faz em um país e a grandiosidade da sociedade que a representa. Não seremos fortes, enquanto químicos, sem uma $S B Q$ forte e representativa. Para isso é preciso que todos os atores estejam unidos. É preciso que a comunidade química brasileira, na sua totalidade, se veja na SBQ."92

As conclusões desse $\operatorname{artigo~}^{91}$, além de corretas, podem ser estendidas a todas as áreas em que a Química atua no Brasil. Um pequeno exemplo da abrangência e qualidade está registrada nas referências citadas neste artigo, e especialmente, as focadas na Formação do Químico, na Inovação e na necessidade de aproximação com o setor empresarial. O fato inegável é que, através da SBQ, a área de Química se capacitou para ordenar seu desenvolvimento e para localizá-la como instrumento de crescimento e competitividade econômica, bem-estar e fortalecimento científico do Brasil.

Nesse sentido, vale retornar ao passado, em 2003, e ressaltar que o artigo "Eixos Mobilizadores em Química", fruto de uma grande articulação realizada no âmbito da SBQ fez uma análise da Pósgraduação em Química do Pais, com dados até o ano de 2000, até então o ano da última avaliação da CAPES. A mais recente avaliação realizada pela CAPES utilizou dados até 2016. Sem qualquer pretensão de fazer uma analise exaustiva sobre os últimos 16 anos, apenas com o objetivo de deflagrar a discussão sobre o tema, faremos uma contextualização das observações extraídas do artigo de 2003 com a atualização dos dados em 2016.

No artigo de $2003^{1}$ está registrado que: "Independentemente do parâmetro considerado, pode-se observar que as taxas de crescimento da área de Química mudam de linear para exponencial a partir dos anos 1990. Observando-se a Figura 3 com dados atualizados até $2016^{93}$ a relação entre o número de publicações e o número de doutores formados entre 1983 e 2000 foi, em média 3,49 enquanto

*o que não temos no Brasil, com a exceção do Instituto SERRAPILHERA (https://serrapilheira.org/), criado em 2017, "uma instituição privada sem fins lucrativos, criada para valorizar a ciência e aumentar sua visibilidade e impacto no Brasil". 
que no biênio 2014 - 2016 foi 7,86. Um número maior do que o dobro $(2,27 \mathrm{x})$ do anterior.

Quanto à evolução do corpo docente (Figura 4), no ano $2000 \mathrm{a}$ pós-graduação em Química no Brasil contava com 906 docentes, enquanto que em 2016 o número de docentes era 2000. Ou seja, um número também maior do que o dobro $(2,21)$. No caso da formação de mestres e doutores, no biênio 1998-2000, foram formados 1111 mestres e 642 doutores, revelando uma relação $\mathrm{m} / \mathrm{d}=1,73$, enquanto que no biênio 2014 - 2016 esses números passam para 3266 mestres e 1878 doutores, mantendo a relação $\mathrm{m} / \mathrm{d}$ praticamente igual, mas com crescimento observado entre os biênios de 2,94 vezes na formação de mestres e 2,93 vezes na de doutores.

Ressalte-se que em 2018 constam na área de Química um total de 117 cursos, sendo 67 mestrados e 47 doutorados acadêmicos, dois mestrados profissionais e um mestrado em rede na área de educação/ensino de Química. Isto é adequado para a área?, isto é adequado para o país??

Certamente sim. Mas, ainda é muito pouco! Os ODS, por exemplo, apontam para um quadro abrangente de novos cenários de participação, sendo que a capacidade do profissional em atuar interdisciplinarmente é cada vez mais um atributo necessário. Precisamos criar novos programas e/ou reconfigurar os programas já existentes, com foco nos desafios atuais que compreendem a formação de conexões entre o setor acadêmico, já muito bem consolidado, e o setor empresarial. Este tem demandas que incluem ampliar a sua taxa de inovação, promover a migração da produção de insumos químicos de uso industrial para os de alto valor agregado, bem como juntar-se ao esforço nacional de implantação da manufatura avançada.

Incluem-se ainda a organização e a administração de toda a cadeia de valor e do ciclo de vida dos produtos, onde será necessária a integração de tecnologias e sistemas digitais, com geração de valores nas cadeias produtivas, na organização de trabalho, nos modelos de negócios e na prestação de serviços inteligentes de internet a jusante, adequados às demandas dos consumidores.

Neste século, a ciência brasileira está diante de uma mudança de paradigma ${ }^{1}$ : se na década de 60 bastava ao professor universitário fazer pesquisa, na década de 80 a publicação de papers era condição obrigatória para ser considerado pesquisador. Várias vezes, nas últimas cinco décadas, o desafio (perguntas) apresentado aos professores pesquisadores mudou (Figura 5). Entretanto, as perguntas mais adequadas seriam: você descobriu o que? E você pretende descobrir o que?

\section{CONSIDERAÇÕES FINAIS}

Vale repetir que não é o objetivo desta publicação fazer uma avaliação profunda da situação atual da área de Química, mas

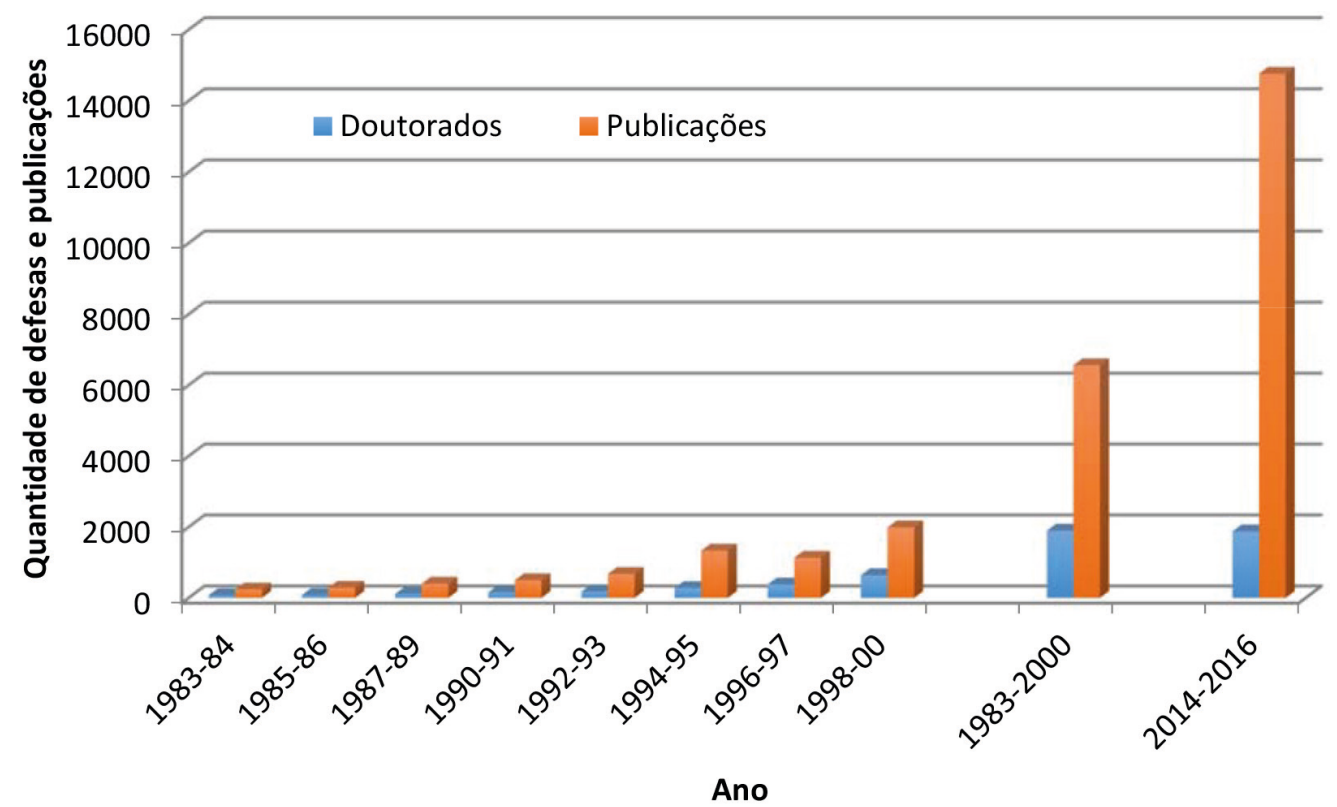

Figura 3. Evolução das teses de doutorado defendidas em Química e o número de publicações em periódicos no exterior" atualizada com os dados de 2016.

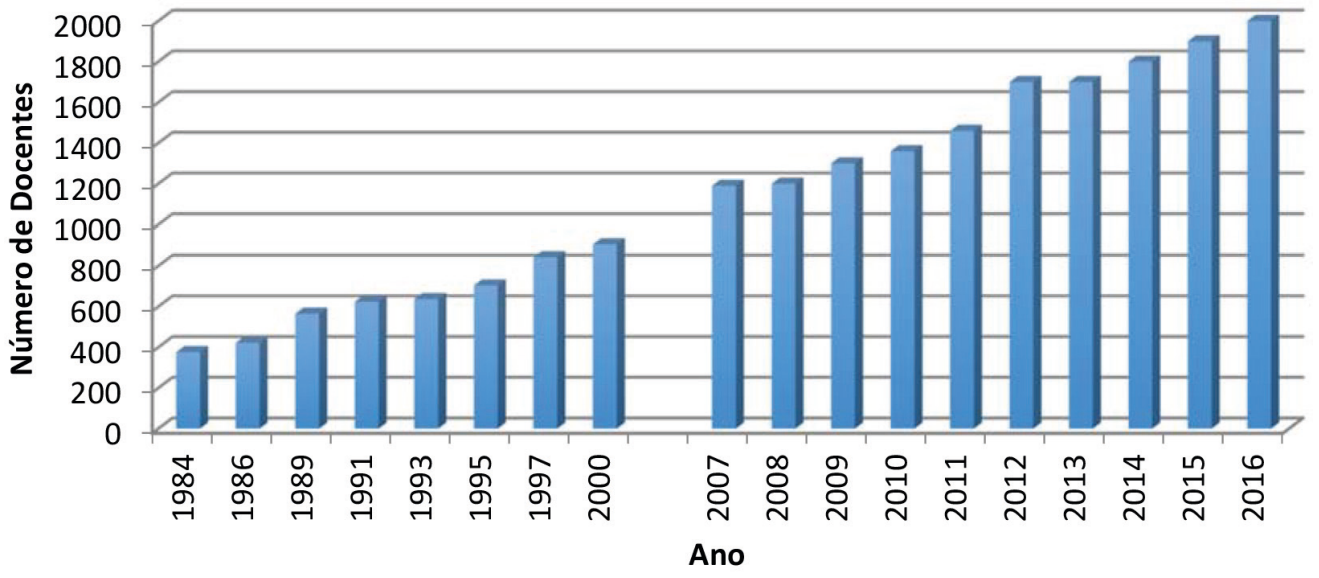

Figura 4. Evolução do Corpo Docente atuando nos Programas de Pos-graduação em Química 1984 -2016. 


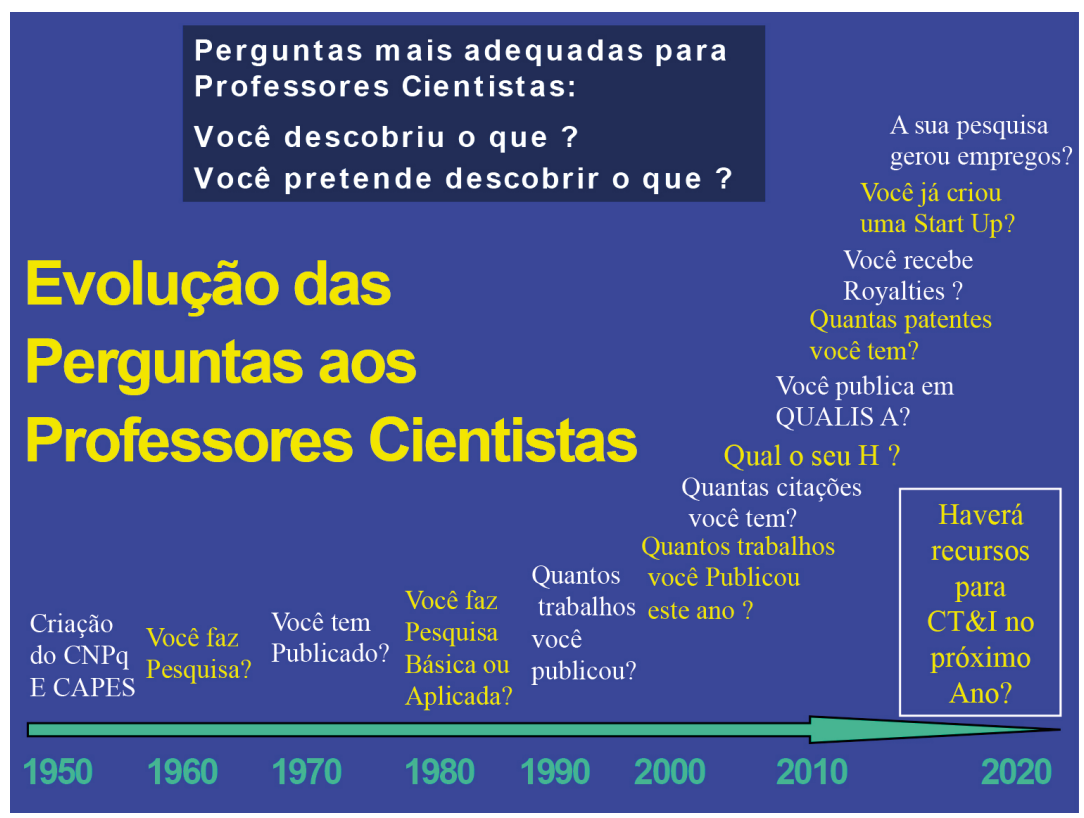

Figura 5. A evolução do paradigma: perguntas feitas aos professores cientistas, adaptado da ref. 1

sim estimular as(os) Colegas, as IES e, especialmente, a SBQ, a iniciarem uma ampla discussão que possa contextualizar a evolução da Química neste século, considerando os setores acadêmico e empresarial. São questões que precisam ser respondidas com urgência e com o "olhar" isento, que só a Sociedade Brasileira de Química poderá fazer. Em resumo, é o momento de revisar e atualizar os Eixos Mobilizadores em Química, considerando o que aconteceu, está acontecendo e poderá acontecer neste jovem século!!

\section{REFERÊNCIAS}

1. de Andrade, J. B.; Cadore, S.; Vieira, P. C.; Zucco, C.; Pinto, A. C.; Quim. Nova 2003, 26, 445.

2. de Andrade, J. B.; Cadore, S.; Vieira, P. C.; Zucco, C.; Pinto, A. C.; Quim. Nova 2004, 27, 358.

3. de Andrade, J. B.; Curi, L. R. L.; Vieira, P. C. Em Necessidades e Perspectivas da Química no Brasil O Futuro do Profissional na Pesquisa, Química Nova: São Paulo, 2005, vol. 28.

4. de Andrade, J. B.; Liza, L. R.; Vieira, P.C.; Quim. Nova 2005, 28(Sup), S5-Editorial.

5. de Andrade, J.B.; Pinto, A.C.; Cadore, S.; Vieira, P.C.; Zucco, C.; Pardini, V. L.; Curi, L.R.L.; Quim. Nova 2005, 28 , S7.

6. Zucco, C.; Quim. Nova 2005, 28, S11.

7. Rebouças, M. V.; Pinto, A. C.; de Andrade, J. B.; Quim. Nova 2005, 28, S14.

8. Araújo e Araújo, M. H.; Lago, R. M.; Oliveira, L C. A.; Cabral, P. R. M.; Cheng, L. C.; Fillion, L. J.; Quim. Nova 2005, 28, S18.

9. Araújo, M. H.; Lago, R. M.; Oliveira, L C. A.; Cabral, P. R. M.; Cheng, L. C; Borges, C.; Fillion, L. J.; Quim. Nova 2005, 28, S26.

10. Machado, S. P.; Melo Filho, J. M.; Pinto, A. C.; Quim. Nova 2005, 28, S41.

11. Alves, O. L.; Quim. Nova 2005, 28, S44.

12. Galembeck, F.; Quim. Nova 2005, 28, S52.

13. Barreiro, E. J.; Fraga, C. A. M.; Quim. Nova 2005, 28, S56.

14. Antunes, O. A. C.; Quim. Nova 2005, 28, S64.

15. Politzer, K.; Quim. Nova 2005, 28, S76.

16. de Oliveira, N. B.; Quim. Nova 2005,28, S79.

17. Miron, M. V. g.; Cavalcanti, F. C. B.; Wongtschowski, P.; Quim. Nova $\mathbf{2 0 0 5}, 28$, S86.
18. de Aquino Neto, F. R.; Quim. Nova 2005, 28, S91.

19. de Aquino Neto, F. R.; Quim. Nova 2005, 28, S95.

20. Antunes, A. M. S.; Menezes, R. P. B.; Quim. Nova 2005, 28, S100.

21. Mansur, A. R.; Quim. Nova 2005, 28, S104.

22. Pereira, A. S.; Bicalho, B.; Lilla S.; de Nucci, G.; Quim. Nova 2005, 28 , S107.

23. Antunes, A. M. S.; Mangueira, A. C. S.; Quim. Nova 2005, 28, S112.

24. Galembeck, F.; Pardini, V.; Quim. Nova 2009, 32, 565-Editorial.

25. Pinto, A. C.; Zucco, C.; de Andrade, J. B.; Vieira, P. C.; Quim. Nova 2009, 32, 567

26. Galembeck, F.; Barbosa, C. A. S.; de Sousa, R. A.; Quim. Nova 2009, 32,571 .

27. Goldemberg, J.; Quim. Nova 2009,32, 582.

28. Bizzo, H. R.; Hovell, A. M. C.; Rezende, C. M.; Quim. Nova 2009, 32, 588.

29. Maia, J. G. S.; Andrade, E. H. A.; Quim. Nova 2009, 32, 595.

30. Ferreira, V. F.; da Rocha, D. R.; da Silva, F. C.; Quim. Nova 2009, 32, 623.

31. Mota, C. J. A.; da Silva, C. X. A.; Gonçalves, V. L. C.; Quim. Nova 2009, 32, 639.

32. da Cunha, P. L. R.; de Paula, R. C. M.; Feitosa, J. P. A.; Quim. Nova 2009, 32, 649 .

33. Silva, R.; Haraguchi, S. K.; Muniz, E. C.; Rubira, A. F.; Quim. Nova 2009, 32, 661.

34. Laranjeira, M. C. M.; de Fávere, V. T.; Quim. Nova 2009, 32, 672.

35. Barreiro, E. J.; Bolzani, V. S.; Quim. Nova 2009, 32, 679.

36. de Oliveira, A. C.; Valentim, I. B.; Goulart, M. O. f.; Silva, C. A.; Bechara, E. J. H.; Trevisan, M. T. S.; Quim. Nova 2009, 32, 689.

37. Costa-Lotufo, L. V.; Wilke, L. V.; Jimenez, P. C.; Epifanio, R. A.; Quim. Nova 2009, 32, 703.

38. Guaratini, T.; Callejon, D. R.; Pires, D. C.; Lopes, J. N. C.; Lima, L. M.; Giannella Neto, D.; Sustovich, C.; Lopes, N. P.; Quim. Nova 2009, 32, 717.

39. Zarbin, P. H. G.; Rodrigues, M. A. C. M.; Lima, E. R.; Quim. Nova 2009, 32, 722 .

40. Mazzetto, S. E.; Lomonaco, D.; Mele, G.; Quim. Nova 2009, 32, 732.

41. de Oliveira, L. G.; Mantovani, S. M.; Quim. Nova 2009, 32, 742.

42. Vichi, F. M.; Mansor, M. T. C.; Quim. Nova 2009, 32, 757.

43. Suarez, P. A. Z.; Santos, A. L. f.; Rodrigues, J. P.; Alves, M. B.; Quim. Nova 2009, 32, 768. 
44. Dabdoub, M. J.; Bronzel, J. L.; Rampin, M. A.; Quim. Nova 2009, 32, 776.

45. Quintella, C. M.; Teixeira, L. S. G.; Korn, M. G.a.; Costa Neto, P. R.; Torres, E. A.; Castro, M. P.; Jesus, C. A. C.; Quim. Nova 2009, 32, 793.

46. Teixeira-Neto, E.; Teixeira-Neto, A. A.; Quim. Nova 2009, 32, 809.

47. Rippel, M. M.; Bragança, F. C.; Quim. Nova 2009, 32, 818.

48. Pinto, A. C.; Zuco, C.; Galembeck, F.; de Andrade, J. B.; Vieira, P. C.; Quim. Nova 2012, 35, 2092.

49. http://qnint.sbq.org.br/, acessada em Agosto de 2018.

50. Pinto, A. C.; Zucco, C.; Galembeck, F.; de Andrade, J. B.; Catalani, L. H.; Vieira, P. C.; Quim. Nova 2012, 35, 2092.

51. Zucco, C. Em Química Hoje; Ivanissevich, A.; Cunha Pinto, A., orgs.; Instituto Ciência Hoje: Rio de Janeiro, 2012.

52. Pinto, A. C.; Zucco, C.; Galembeck, F.; de Andrade, J. B.; Catalani, L. H.; Vieira, P. C.; Quim. Nova 2013, 36, 1481-Editorial.

53. Mota, C. J. A.; Monteiro, R. S.; Quim. Nova 2013, 36, 1483.

54. Antunes, A. M. S.; Quim. Nova 2013, 36, 1491.

55. Hatje, V.; da Costa, M. F.; da Cunha, L. C.; Quim. Nova 2013, 36, 1497.

56. Pinto-Zevallos, D. M.; Zarbin, P. H. G.; Quim. Nova 2013, 36, 1509.

57. Ferreira, V. F.; da Silva, F. C.; Ferreira, P. G.; Quim. Nova 2013, 36, 1514.

58. Dimer, F. A.; Friedrich, R. B.; Beck, R. C. R.; Guterres, S. S.; Pohlmann, A. R.; Quim. Nova 2013, 36, 1520.

59. Sinisterra, R. D.; Speziali, M. G.; Guimarães, P. P. G.; da Silva, A. M.; Quim. Nova 2013, 36, 1527.

60. Zarbin, A. J. G.; Oliveira, M. M.; Quim. Nova 2013, 36, 1533.

61. da Rocha, G. O.; de Andrade, J. B.; Guarieiro, A. L. N.; Guarieiro, L. L. N.; Ramos, L. P.; Quim. Nova 2013, 36, 1540.

62. Dias, L. C.; Dessoy, M. A.; Guido, R. V. C.; Oliva, G.; Andricopulo, A. D.; Quim. Nova 2013, 36, 1552.

63. Pinto, A. C.; Barreiro, E. J.; Quim. Nova 2013, 36, 1557.

64. Teruya, L. C.; Marson, G. A.; de Rezende, C. M.; Viana, M. H.; Quim. Nova 2013, 36, 1561

65. dos Santos, W. L. P.; Porto, P. A.; Quim. Nova 2013, 36, 1570.

66. de Oliveira, L. G.; Pupo, M. T.; Vieira, P. C.; Quim. Nova 2013, 36, 1577 .

67. Gonçalves, C. C. S.; Marsaioli, A. J.; Quim. Nova 2013, 36, 1587.

68. Braga, A. L.; Lüdtke, D. S.; Schneider, P. H.; Andrade, L. H.; Paixão, M. W.; Quim. Nova 2013, 36, 1591.

69. Galembeck, F.; Quim. Nova 2013, 36, 1600.

70. Funari, C. S.; Castro-Gamboa, I.; Cavalheiro, A. J.; Bolzani, V. S.; Quim. Nova 2013, 36, 1605.

71. Pinto, A.C.; J. Braz. Chem. Soc. 2012, 23, 1409-Editorial.

72. https://profqui.iq.ufrj.br/, acessado em Agosto de 2018.

73. Andricopulo, a. D.; de Andrade, J. B. Quim. Nova 2015, 38, 1139-Editorial.
74. http://www.un.org/ga/search/view_doc.asp?symbol=A/ RES/70/1\&Lang=E, acessado em Agosto de 2018.

75. https://nacoesunidas.org/pos2015/agenda2030/, acessado em Abril de 2018.

76. Fernandes, J. A. C.; da Fonseca, R.; Branco, F. C.; Marques, M. C. C.; Cunha, S. F.; Giágio, M.; Cunha, F.; Morelli, G.; Gonçalves, E. Em Mapa Estratégico da Indústria 2018-2022 Confederação Nacional da Indústria. CNI: Brasília, 2018.

77. https://abiquim.org.br/comunicacao/noticia/3824, acessado em Setembro de 2018.

78. https://www.japanindustrynews.com/2017/08/japans-society-5-0-goingbeyond-industry-4-0 acessado em Agosto de 2018.

79. http://www8.cao.go.jp/cstp/english/society5_0/index.html, acessado em Agosto de 2018.

80. http://www.un.org/esa/population/publications/worldageing19502050/ pdf/90chapteriv.pdf, acessado em Agosto de 2018.

81. Ciência, Tecnologia e Inovação para um Brasil competitivo Roberto Mendonça Faria, e composto pelos pesquisadores Jacobus Willibrordus Swart, Jailson Bittencourt de Andrade e João Batista Calixto. CAPES/ SBPC, 2011

82. https://www.embrapii.org.br/ acessado em Setembro de 2018.

83. http://www.portaldaindustria.com.br/senai/canais/inovacao-e-tecnologia/ institutos-senai-de-inovacao/, acessado em Agosto de 2018.

84. http://institutos.senai.br/institutos/, acessado em Agosto de 2018.

85. http://www.senaicimatec.com.br/sobre/, acessado em Agosto de 2018.

86. http://www.telegraph.co.uk, acessado em Agosto de 2018.

87. Guaratini, T., Knowledge-Intensive Business Services in Brazil: Entrepreneurship in a Stimulating Scenario. 2016, ACS Symposium Series, Vol. 1219, Chapter 14, pp 123-129, DOI: 10.1021/bk-2016-1219. ch014.

88. http://www.brasilitplus.com/brasilit/upload/ download/1416332923startups.pdf, acessado em Junho de 2018.

89. https://www1.folha.uol.com.br/mercado/2018/03/investimento-emstartups-brasileiras-bate-recorde-em-2017.shtml, acessado em março de 2018 .

90. http://www.planalto.gov.br/ccivil_03/_Ato2015-2018/2018/Decreto/ D9283.htm, acessado em Junho de 2018.

91. http://www.nap.edu/catalog.php?record_id=13299, 2012 ISBN 978-0309-22428-4, acessado em Junho de 2018.

92. Zarbin, A. J. G.; Quim. Nova 2017, 40, 614.

93. Monteiro, A. L.; Forlan, M.; Suarez, P.A., "Relatório de Avaliação Quadrienal 2017- Quimica", Ministério da Educação, Coordenação de Aperfeiçoamento de Pessoal de Nível Superior, Diretoria de Avaliação, $77 \mathrm{pg}, 2017$. 